mainly a flake culture of distinct facies which may range from the Early to late Middle or even Upper Palæolithic. Workshops belonging to this Soan industry are numerous below the Potwar loess-like silt.

During the last two months, various excursions were made to Upper Sind, Central and Southern India. Along the Narbadda River, Dr. Teilhard and I collected Chellean and Acheulean tools from beds containing the Narbadda fauna of Middle Pleistocene age. Here also were found artefacts belonging to the Soan culture.

Paterson, Drummond and Krishnaswami studied the prehistoric collections in the museums at Lahore, Benares, Calcutta, Madras, Trivandrum, Colombo and Bombay, and field work was carried out by them in Madras and Bombay presidencies.
They reported a widespread occurrence of the Soan culture, of a microlithic industry, and of a proto-Neolithic culture. The early Neolithie in these collections appeared to be akin to that of northern Europe, though there occur types similar to the latest Upper Palæolithic of North Africa.

The artefact collection, numbering more than four thousand specimens, will be worked out by Paterson and Drummond at the Arehæological Museum of the University of Cambridge.

The researches were made possible through the support of the Carnegie Institution of Washington, the American Philosophical Society, the Royal Society of London and the University of Cambridge. The co-operative policy of the Government of India and of the Geological and Archæological Surveys of India is gratefully acknowledged.

\title{
Food from Wood
}

$\mathrm{T}$ HE suggestion has recently been made that as much food might be obtained per acre of woodland as per acre of arable land, if the wood be so treated as to yield sugar. The production of sugar from wood has been a subject of much research, especially in Germany and the United States. There is no doubt that it can be achieved, not only on a small laboratory scale but also in commercial plant operation; the difficulties that have had to be overcome have been those of chemical engineering rather than of chemical reactions. There is, however, a very real doubt whether such a process is justifiable, save perhaps in time of national emergency (for which purpose it was developed in Germany during the Great War), or whether it can ever be economically a sound proposition.

From a material point of view, timber is grown for two main purposes-either for use as a structural material or for its cellulose content. There are perhaps few structural uses of timber that could not be satisfied by other materials. Cellulose, however, is as yet quite indispensable, not merely as pulp and paper, but also in its myriad new uses for textiles or rayon, lacquers, cellophane, etc. To split up such a valuable raw material to sugar is certainly unsound from the point of view of the proper utilisation of natural resources, and only justifiable if-the products cannot be obtained from any other source. The agriculturist will answer that sugar of a purer and more usable type may be obtained directly from sugar beet, or from cane, or can be obtained far more simply from starchy crops such as potatoes or maize. Sugar beet is capable of yielding 2-3 tons of sugar per acre, and sugar cane $4-5 \frac{1}{2}$ tons per acre. The starch in potatoes amounts to $1 \frac{1}{2}-2$ tons per acre, or in maize, 1 ton per acre, equivalent to an almost equal weight of sugar.

To make a comparison of these yields with those possible from woodland is difficult, inasmuch as the latter is obviously not an annual crop. The faster growing soft woods (conifers) may be said to give more than 300 tons of timber per acre per 100 years, or 3 tons per acre per year. The maximum yield of wood sugar so far claimed is two thirds of the weight of the wood, or 2 tons per acre on an annual basis. This calculation is rather questionable because the annual rate of increase of saplings is much greater for the first ten to twenty years than at maturity, and the yield of wood sugar per acre obtainable from young growth might be at a higher level. Against this must be set the fact that the rate of growth of most woods is considerably below that of the very vigorous soft woods such as silver fir.

The most serious objection that can be raised to the process, however, is the nature of the sugar produced. Whereas cane and beet give almost exclusively sucrose, that from wood is a mixture of several sugars, not all of them of equal value as food to man or animals, or even of equal availability for biological fermentations. The chief constituents of woods are cellulose, hemicelluloses and lignin. The proportions found usually lie within the following | orcentage limits-cellulose, 50-60, hemicelluloses, 10-15, lignin, 20-30. The cellulose of woods is not identical with the standard cellulose of cotton, but contains considerable amounts of the pentosan-xylan-particularly in the case of 
hard woods, in which as much as 25 per cent of the wood cellulose may be xylan. Softwood cellulose contains less xylan but has in addition mannan. The hemicelluloses are carbohydrates built up from a number of sugars, such as galactose, arabinose, mannose and xylose, and may easily be split up into these components. Wood sugar is a mixture of all these sugars with glucose from the true cellulose, and even if complete breakdown of the wood is effected, the sugar mixture obtained may not contain more than 60 per cent glucose. It is important to keep this fact in mind when considering the possible uses of wood sugar.

Much of the work on the saccharification of wood has been directed to the production of alcohol from the product by fermentation. Of the sugars present only glucose and mannose are fermentable by ordinary yeasts, the pentose sugars and galactose remaining behind. Since the yield of alcohol from a fermentable sugar is less than 50 per cent, the amount of alcohol to be obtained from wood is not great. Yields of 25-30 gallons of alcohol per ton of sawdust have been obtained commercially, and higher amounts in laboratory scale experiments. The pentose sugars unattacked by the yeast may afterwards be fermented with special bacteria to give largely lactic acid and a little acetic acid. High yields of acids may alternatively be ob. tained by direct fermentation with such organisms as produce lactic acid from both hexoses and pentoses.

For use as food or as a raw material in the production of food, wood sugar may be employed in several ways. It may be fed directly as cattle food and has been said to have practically the same nutritive value as barley flour. The availability of the pentose sugars in the mixture is, however, a matter of doubt; xylose is little utilised by animals or man. The food value probably lies therefore in the glucose and mannose present. Alternatively, the glucose may be separated out in a pure condition and used in other foods. Glycerol might be obtained by modified yeast fermentations in the presence of sulphite, which results in a yield of 15-20 per cent of the sugar fermented, or protein obtained by using the wood sugar solution as a nutrient for yeasts or fungi under such conditions as result in the production of maximum yields of microbial tissue.

The actual production of wood sugar may be achieved in two ways. The complex carbohydrates of the wood may be split up either by dilute acids at high temperatures and pressures or by concentrated acids at ordinary temperatures. The latter procedure, which is the basis of the Bergius process, operated in Germany, gives both higher yields of sugar and higher percentages of fermentable sugar than the former. Unless the treatment is prolonged and the temperature high, dilute acids do not break down the true cellulose completely. Degradation products of the sugars, such as furfural and humus substances, are also formed. Concentrated acids, on the other hand, result in complete solution of the wood, leaving only the lignin behind. The wood in the form of chips is treated with 7 parts of 40 per cent hydrochloric acid in a continuously operated battery of 8-10 vessels. The acid is removed from the extract by vacuum distillation to give a product containing 60 per cent sugar and 8 per cent hydrochloric acid. An atomising drier concentrates this to 90 per cent sugar content with only 1 per cent hydrochloric acid.

The engineering difficulties in the recovery of the acid without damage to the product have been very great, but it is now claimed that the total acid loss is not more than 10 per cent calculated on the sugar obtained. The yield of sugar from a coniferous wood is 66 per cent, which approaches the theoretical. Although the action of the strong acid results in such an extensive breakdown, the true cellulose fraction is not completely split up to glucose but remains in the form of cellulose dextrins, which consist of cellulosic fragments each built up of a few glucose units. These are not fermentable, and to obtain the glucose from them an aqueous solution must be boiled with dilute acid for a short time. The wood sugar mixture then obtained may be separated or utilised in one of the ways mentioned above.

In normal circumstances, the commercial production of wood sugar, though a remarkable feat in chemical engineering, cannot be taken as any threat to agriculture in view of the heterogeneous nature of the product obtained, and the growing world shortage of timber for pulp. Claims have been made that in the most favourable situation and conditions glucose might be obtained from this source more cheaply than sucrose from sugar beet. Ordinarily, however, there must be a wide disparity in costs, and sugar beet cultivation has the advantage additionally of giving much employment. One development which might make the wood sugar process economically possible in normal times would be a demand for lignin for some manufacturing purpose. At present the residual portion of the wood, consisting almost exclusively of lignin, remains unutilised. This amounts to $20-30$ per cent of the weight taken. The possibilities of lignin as a raw material in industry have not been adequately considered, perhaps because the constitution is still obscure. Because of its marked resistance to biological attack, and inertness to strong chemicals, other than oxidising agents, it should find a useful outlet. The production of wood sugar and lignin from wood would then be inore defensible than that of sugar alore. A. G. N. 